\title{
Osmotic stress affects water relations, growth, and nitrogen fixation in Phaseolus vulgaris plants
}

\author{
Sameh Sassi Aydi · Samir Aydi · \\ Esther Gonzalez $\cdot$ Chedly Abdelly
}

Received: 7 April 2008/Accepted: 7 April 2008/Published online: 25 April 2008

(C) Franciszek Górski Institute of Plant Physiology, Polish Academy of Sciences, Kraków 2008

\section{Erratum to: Acta Physiol Plant}

\section{DOI 10.1007/s11738-008-0141-y}

Two errors appeared in our article

We wish to add the following erratum:

Error 1. In the Materials and methods section, paragraph Nitrogen status and nitrogenase activity, to read "Two picks appear the first one corresponds to ethylene and the second one to acetylene" instead of
"Two picks appear the first one corresponds to ethylene and the second one to ethylene"

Error 2. In the reference section, Galvez et al. (2005) has to read: 2251-2261 instead of 2561.

The online version of the original article can be found under doi:10.1007/s11738-008-0141-y.

S. Sassi Aydi · S. Aydi · C. Abdelly $(\bowtie)$ Laboratoire d'Adaptation des Plantes aux Stress Abiotiques, Centre de Biotechnologie de Borj Cedria, BP 901, 2050 Hammam-Lif, Tunisia

e-mail: chedly.abdelly@cbbc.rnrt.tn

E. Gonzalez

Departamento de Ciencias del Medio Natural, Universidad Pùblica de Navarra,

Campus de Arrosadía, 31006 Pamplona, Spain 